\title{
Nanoscale grain growth behaviour of CoAl intermetallic synthesized by mechanical alloying
}

\author{
S N HOSSEINI*, M H ENAYATI and F KARIMZADEH \\ Department of Materials Engineering, Isfahan University of Technology, Isfahan 84156-83111, Iran
}

MS received 23 January 2013; revised 4 April 2013

\begin{abstract}
Grain growth behaviour of the nanocrystalline CoAl intermetallic compound synthesized by mechanical alloying has been studied by isothermal annealing at different temperatures and durations. X-ray diffraction method was employed to investigate structural evolutions during mechanical alloying and annealing processes. The disordered CoAl phase with the grain size of about $6 \mathrm{~nm}$ was formed via a gradual reaction during mechanical alloying. The results of isothermal annealing showed that the grain growth behaviour can be explained by the parabolic grain growth law. The grains were at nanometric scale after isothermal annealing up to $0.7 T_{\mathrm{m}}$. The grain growth exponent remained constant above $873 \mathrm{~K}$ indicating that grain growth mechanism does not change at high temperatures. The calculated activation energy indicated that the grain growth mechanism in the disordered CoAl phase at high temperatures was diffusing Co and Al atoms in two separate sublattices. Furthermore, an equation has been suggested to describe the grain growth kinetics of nanocrystalline CoAl under isothermal annealing at temperatures above $873 \mathrm{~K}\left(T / T_{\mathrm{m}} \geq 0 \cdot 5\right)$.
\end{abstract}

Keywords. Intermetallic compounds; nanostructures; grain growth; isothermal annealing; mechanical alloying.

\section{Introduction}

Grain growth in polycrystalline materials, in general, occurs to decrease the free energy of the system by decreasing the total grain boundary energy. In nanocrystalline (nc) materials, high amount of grain boundary leads to a significant fraction of high energy and provides a strong driving force for grain growth. Since the unique properties of these materials are closely related to fine grain size and large volume fraction of the grain boundaries, it is of vital importance to maintain the microstructure at a nanometric scale during consolidation or service as structural components at elevated temperatures (Lee et al 2001; Liu and Mucklich 2001; Liu et al 2006; Kazeminezhad 2009; Bera et al 2013). With this regard, many studies have been focused on the grain growth behaviour of nc materials (Nygren and Shen 2003; Chen et al 2011; Wu et al 2011).

Although, different grain growth models were proposed for nc materials taking into account of the impurities and solute drags (Tengen et al 2007), it was reported that some nc materials still obeyed the parabolic kinetic equation of grain growth for isothermal annealing in the form (Kambara et al 2000; Thein et al 2006; Ren et al 2008):

\footnotetext{
*Author for correspondence (golenarges63@yahoo.com)
}

$$
D^{n}-D_{0}^{n}=K t,
$$

where $D, D_{0}$ and $n$ are the mean grain size at time $t$, mean initial grain size and the grain-growth exponent, respectively. $K$ is a constant that satisfies the following equation (Kambara et al 2000; Thein et al 2006; Ren et al 2008):

$$
K=K_{0} \exp \left(\frac{-Q}{R T}\right)
$$

where $Q$ is the activation energy required for grain growth and $K_{0}, R$ and $T$ are constant, gas constant and temperature, respectively. Equations (1) and (2) can be rewritten as (Ren et al 2008)

$$
D^{n}-D_{0}^{n}=K_{0}\{\exp [-Q /(R T)]\} t .
$$

In addition, the rate of grain growth, $\mathrm{d} D / \mathrm{d} t$, can be $\mathrm{de}$ rived as:

$$
\log (\mathrm{d} D(t) / \mathrm{d} t)=-(n-1) \log D(t)+\log K-\log n .
$$

The relationship between $\log \mathrm{d} D(t) / \mathrm{d} t$ and $\log D(t)$ gives the values of $n$ and $K$. Also, the activation energy, $Q$ can be obtained from (3) by plotting $\log \left[\left(D^{n}-D_{0}^{n}\right) / t\right]$ as a function of $1 / T$. A variety of $n$ values have been reported for various systems and $n$ value can be a useful factor to describe the difference in growth mechanism between different systems (Kambara et al 2000). 
The aim of this work is to investigate thermal stability and grain growth kinetics of the nanostructured $\mathrm{CoAl}$ synthesized by mechanical alloying (MA).

\section{Experimental}

MA of the Co-50 at\% Al powder blend was carried out at an ambient temperature in a planetary high energy ball mill, using hardened chromium steel vial and balls. No process control agent (PCA) was used. The related parameters for MA are presented in table 1. Isothermal annealing was performed to investigate the grain growth kinetics of milled powders. Powder samples were sealed and then annealed in a conventional tube furnace. The annealing process parameters are displayed in table 1 . Xray diffraction (XRD) technique by a Philips X'PERT MPD diffractometer $(\mathrm{CuK} \alpha$ radiation: $\lambda=0.154 \mathrm{~nm}$ at $20 \mathrm{kV}$ and $30 \mathrm{~mA}$ ) was used to characterize phase composition and structural changes of the powders. The Williamson-Hall formula (Williamson and Hall 1953) was used to estimate the grain size and internal strain using broadening of XRD peaks.

Table 1. Parameters for MA and heat treatment.

\begin{tabular}{ll}
\hline Parameters & \multicolumn{1}{c}{ Value } \\
\hline Rotation speed (r/min) & 600 \\
Ball to powder weight ratio & $15: 1$ \\
Ball milling time (h) & $1,3,6,10,25$ and 45, respectively \\
Protective atmosphere & $\mathrm{Ar}$ \\
Annealing temperature (K) & $873,973,1073$ and $1173 \mathrm{~K}$, \\
& respectively \\
Holding time (h) & $0 \cdot 5,1$ and $1 \cdot 5$ \\
Cooling mode & Cooling in air \\
\hline
\end{tabular}

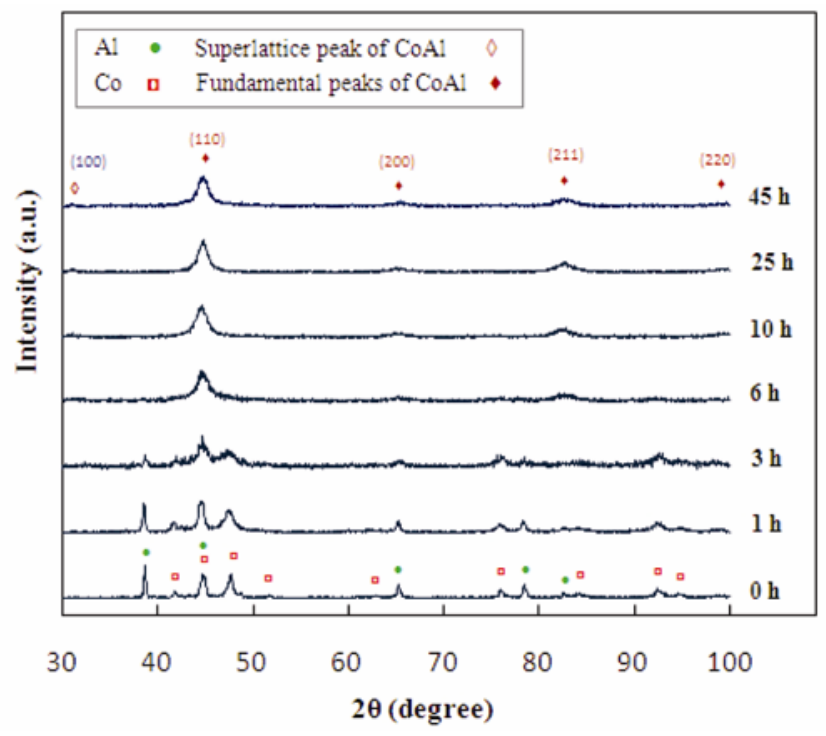

Figure 1. XRD patterns of $\mathrm{Co}_{50}-\mathrm{Al}_{50}$ powder mixture at different MA times.

\section{Results and discussion}

\subsection{MA and phase evolution}

Figure 1 shows XRD patterns of the $\mathrm{Co}_{50} \mathrm{Al}_{50}$ powder mixture after different milling times. At the early stages of MA, progressive peak broadening occurred as a result of the increase in internal strain and reduction in grain size due to heavy deformation during MA. A new phase of B2-CoAl was detected after $3 \mathrm{~h}$ of MA. Transformation of elemental $\mathrm{Co}$ and $\mathrm{Al}$ powder mixture to the CoAl intermetallic phase was completed after $10 \mathrm{~h}$ MA. The detection of superlattice reflection (100) indicates that the B2-CoAl phase has an ordered structure. The long range order parameter $(S)$ was calculated considering the (100) superlattice reflection and (110) fundamental reflection of cubic B2 structure formed by MA using the following formula (Mousavi et al 2008):

$$
S=\sqrt{\frac{\left(I_{(100)} / I_{(110)}\right)_{\mathrm{obs}}}{\left(I_{(100)} / I_{(110)}\right)_{\mathrm{std}}}},
$$

where subscripts 'obs' and 'std' stand for observed and standard ratios of the intensities of the mentioned diffracting atomic planes. Here, standard ratio refers to a completely ordered structure (Mousavi et al 2008). The $S$ parameter, grain size and lattice strain of the B2-CoAl were calculated for different MA times and are presented in table 2. As can be seen, the $S$ value is equal to 1 during $6-10 \mathrm{~h}$ milling, suggesting that formed B2-CoAl is fully ordered. The $S$ value decreases and reaches a constant value of about 0.82 after long milling periods. The grain size of the formed $\mathrm{CoAl}$ is about $6 \mathrm{~nm}$ that remains approximately constant with further milling. The mechanism of $\mathrm{CoAl}$ disordering was entirely investigated in our previous work (Hosseini et al 2011), which implies that disordering in $\mathrm{B} 2-\mathrm{CoAl}$ compound occurs with triple defect formation.

\subsection{Heat treatment}

In order to investigate grain growth, annealing of the as-milled powder was performed at different temperatures and durations. The corresponding XRD patterns are shown in figure 2 . The grain size of nanocrystalline

Table 2. Structural characteristics of $\mathrm{CoAl}$ phase at different MA times.

\begin{tabular}{rccc}
\hline MA time $(\mathrm{h})$ & Grain size $(\mathrm{nm})$ & $\varepsilon(\%)$ & $S$ \\
\hline 6 & 6 & $0 \cdot 75$ & 1 \\
10 & 7 & $0 \cdot 36$ & 1 \\
25 & 7 & 1.41 & $0 \cdot 82$ \\
45 & 6 & 1.63 & $0 \cdot 82$ \\
\hline
\end{tabular}



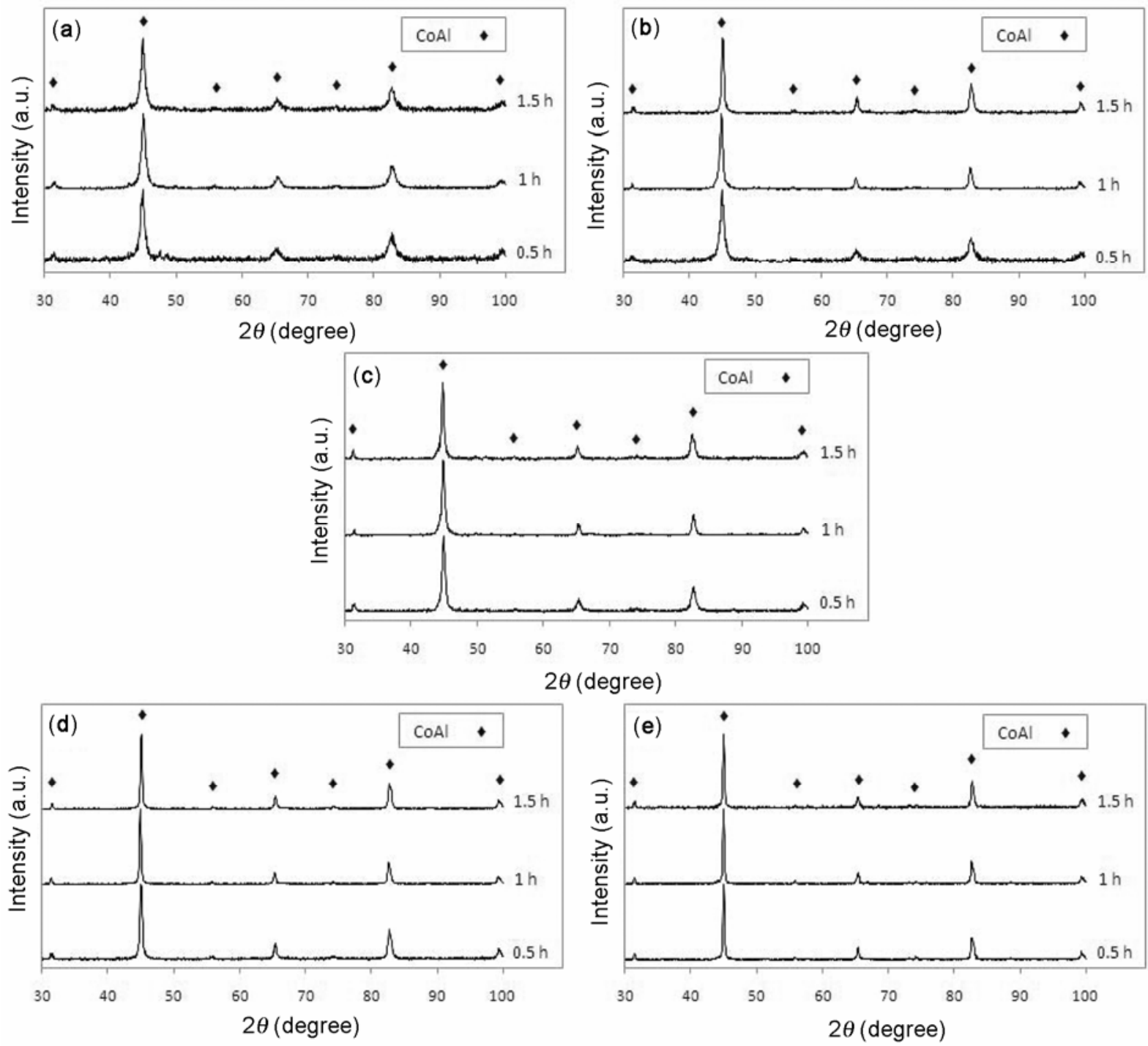

Figure 2. XRD patterns of isothermally annealed powders at (a) 873, (b) 973, (c) 1073, (d) 1173 and (e) $1273 \mathrm{~K}$ for $0 \cdot 5,1$ and $1 \cdot 5 \mathrm{~h}$.

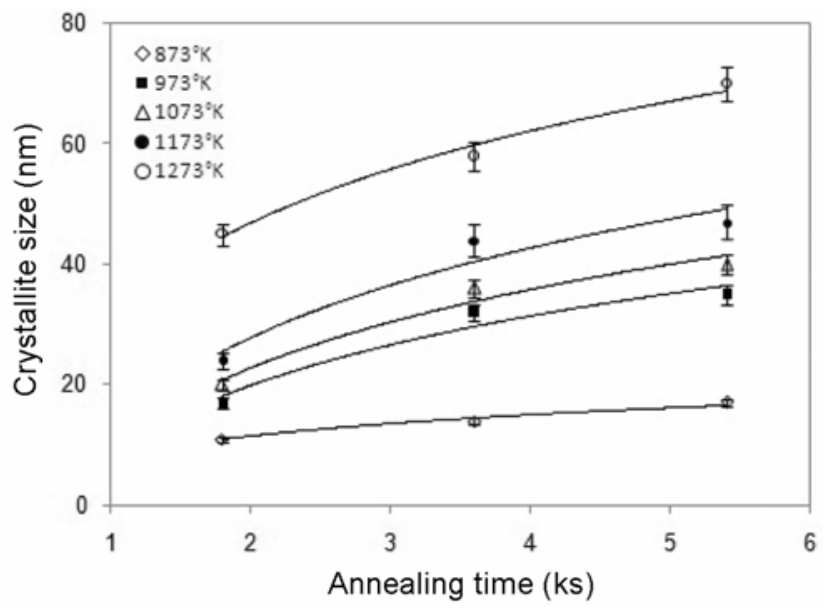

Figure 3. Grain size of $\mathrm{CoAl}$ as a function of annealing time for different temperatures.
CoAl, calculated from XRD patterns, are plotted as a function of annealing time (see figure 3 ). As expected, the grain size increases with increase in temperature. The grain size does not hugely vary with annealing time especially at $T \geq 973 \mathrm{~K}$. The grain size increases rapidly first and then almost evenly at longer annealing times. This can be interpreted as a result of the decrease in the interfacial energy during grain growth (Suryanarayana 2001). The plots of $\log \mathrm{d} D(t) / \mathrm{d} t$ vs $\log (D)$ (figure 4) were obtained by fitting the data to (4) using a nonlinear fitting route. The value of $n$ is about 3 for $873 \mathrm{~K}$ and reaches to a constant value of 4 at higher temperatures $\left(T / T_{\mathrm{m}} \geq 0 \cdot 5\right)$. It is reported that $n$ value depends on grain growth mechanism (Kambara et al 2000; Thein et al 2006). So, it is known that grain growth mechanism of the nanocrystalline CoAl compound is same at the temperature range of 973-1273 K. Normal grain growth of pure mate- 
rials $(n=2)$ is controlled by curvature-driven migration of grain boundaries. When $n=3$, grain growth process is governed by volume diffusion. If $n=4$, the stochastic jumping of atoms across the grain boundaries is predominant. As observed experimentally, the $n$ values usually ranges from 2 to $>5$ for conventional pure metals as well as some of the MAed intermetallic compounds, e.g. nanocrystalline Fe with $n$ value in the range of 3-11 (Liu et al 2006; Thein et al 2006; Ren et al 2008; Kazeminezhad 2009). In conventional materials, the value of $n$ is dependent on both mobility and energy of the grain boundaries. It is reported (Thein et al 2006; Ren et al 2008) that for nano-Fe, similar to coarse-grained $\mathrm{Fe}$, $n$ decreases towards 2 as $T / T_{\mathrm{m}}$ increases to $\approx 0 \cdot 6$. The growth exponent, $n$, obtained in this work indicates that nano-CoAl shows high resistance against grain growth compared to nano-Fe or conventional coarse-grained Fe. In addition, this value offers that the grain growth

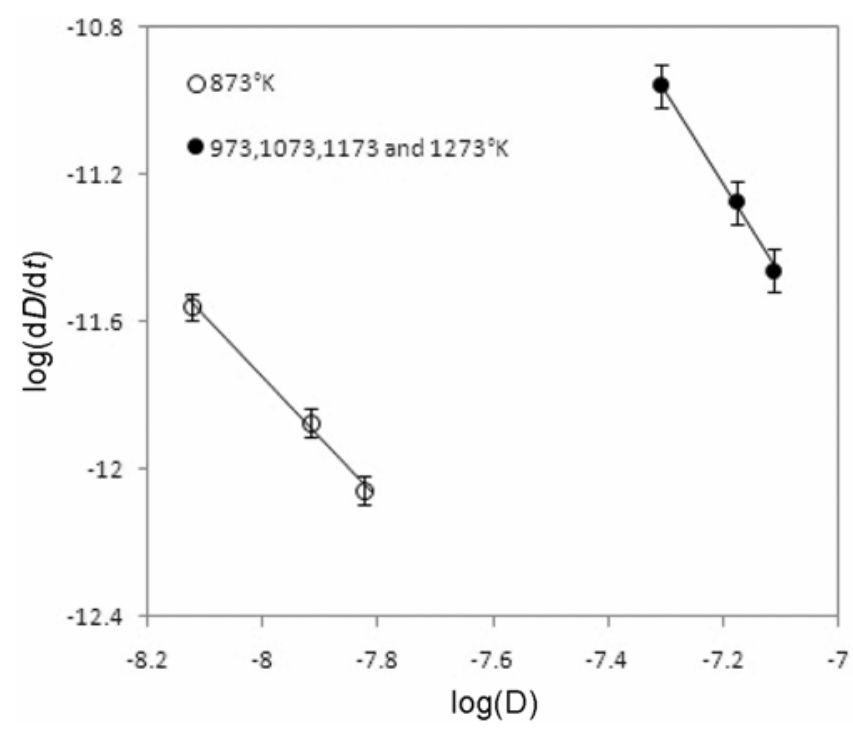

Figure 4. Plot of $\log \mathrm{d} D(t) / \mathrm{d} t$ vs $\log (D)$ for CoAl phase at different annealing temperatures.

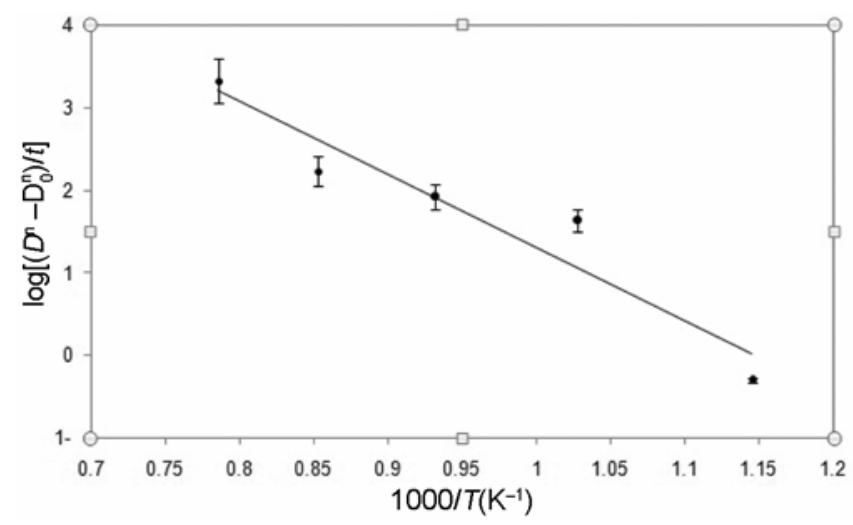

Figure 5. Plot of $\log \left[\left(D^{\mathrm{n}}-\mathrm{D}_{0}^{\mathrm{n}}\right) / t\right]$ against $1000 / T$ for $\operatorname{CoAl}$ grains. mechanism of the nanostructured $\mathrm{CoAl}$ at temperatures above $873 \mathrm{~K}\left(T / T_{\mathrm{m}} \approx 0.5\right)$ can be the random jump of atoms across the grain boundaries. Considering the fact that nanostructured $\mathrm{CoAl}$ consists of nanometer-sized grains and has a large volume fraction of grain boundaries, grain growth through atom diffusion in these boundaries is expected to be much easier than that through conventional lattice diffusion.

By plotting $\log \left[\left(D^{n}-D_{0}^{n}\right) / t\right]$ vs $1 / T$ and fitting a straight line to the data points (figure 5), the activation energy for grain growth of nanocrystalline CoAl compound was calculated to be $175 \pm 20 \mathrm{~kJ} / \mathrm{mol}$. This value of $Q$ is quite smaller than the activation energy of both inter-diffusion in conventional CoAl $(\approx 432 \mathrm{~kJ} / \mathrm{mol})$ (Nakamura et al 2002) and self-diffusion of Co in conventional $\mathrm{CoAl}(\approx 416 \mathrm{~kJ} / \mathrm{mol})$ (Nakamura and Iijima 2005). But, it is approximately close to the activation energy for diffusion of $\mathrm{Co}$ in $\mathrm{Al}(83 \mathrm{~kJ} / \mathrm{mol})$ (Agarwal et al 1964) and also the activation energy of Al volume selfdiffusion (144 kJ/mol) (Liu et al 2006). As mentioned before, the CoAl phase has a disordered structure with the triple defects formation mechanism in which CoAl structure is maintained by remaining $\mathrm{Al}$ atoms on their own sublattices. So, it can be said that the grain growth in disordered CoAl phase is accomplished by diffusing Co and $\mathrm{Al}$ atoms in two separate $\mathrm{Al}$ and Co sublattices.

Consequently, the grain growth kinetics of nanocrystalline CoAl under isothermal annealing at temperatures above $873 \mathrm{~K}$ can be well described using:

$$
D^{4}-D_{0}^{4}=6 \times 10^{13}\{\exp [-175 /(R T)]\} t .
$$

Above (6) provides the means by which the grain size of nanocrystalline $\mathrm{CoAl}$ can be controlled by simply governing the annealing temperature and time.

\section{Conclusions}

Nanocrystalline disordered CoAl phase with the grain size of about $6 \mathrm{~nm}$ was synthesized by MA. The grains grew after isothermal annealing up to $0.7 T_{\mathrm{m}}$ but still remained below $100 \mathrm{~nm}$. The grain growth behaviour was well described by the parabolic kinetics equation. The grain growth exponents and activation energies offered the mechanism of diffusing $\mathrm{Co}$ and $\mathrm{Al}$ atoms in the two separate sublattices at high temperatures. The equation

$$
D^{4}-D_{0}^{4}=6 \times 10^{13}\{\exp [-175 /(R T)]\} t,
$$

was suggested to describe the grain-growth kinetics of nanocrystalline $\mathrm{CoAl}$ during isothermal annealing at temperatures above $0.5 T_{\mathrm{m}}$.

\section{Acknowledgements}

We gratefully acknowledge $\mathrm{T}$ Mousavi for her useful assistance. 


\section{References}

Agarwal R P, Murarka S P and Anand M S 1964 Acta Met. 12871

Bera S, Ghosh Chowdhury S, Estrin Y and Manna I 2013 J. Alloys Compd. 548257

Chen X, Yu X, Zhang J, Li M, Sun H and Liu Q 2011 Solid State Sci. 132165

Hosseini S N, Mousavi T, Karimzadeh F and Enayati M H 2011 J. Mater. Sci. Technol. 27601

Kambara M, Uenishi K and Kobayashi K F 2000 J. Mater. Sci. 352897

Kazeminezhad M 2009 Bull. Mater. Sci. 3219

Lee J, Zhou F, Chung K H, Kim N J and Lavernia E J 2001 Metall. Mater. Trans. 323109

Liu F, Yang G, Wang H, Chen Z and Zhou Y 2006 Thermochim. Acta 443212

Liu K W and Mucklich F 2001 Acta Mater. 49395
Mousavi T, Karimzadeh F and Abbasi M H 2008 Mater. Sci. Eng. 48746

Nakamura R and Iijima Y 2005 Intermetallics 13163

Nakamura R, Takasawa K, Yamazaki Y and Iijima Y 2002 Intermetallics 10195

Nygren M and Shen Z 2003 Solid State Sci. 5125

Ren R, Wu Y C, Tang W M, Wang F T, Wang T G and Zheng Z X 2008 Trans. Nonferrous Met. Soc. China 1866 Suryanarayana C 2001 J. Prog. Mater. Sci. 461

Tengen T B, Wejrzanowski T, Iwankiewicz $\mathrm{R}$ and Kurzydłowski K J 2007 Solid State Phenom. 129 157

Thein M A, Lu L and Lai M O 2006 Compos. Sci. Tech. 66 531

Williamson G K and Hall W H 1953 Acta Met. 122

Wu S P, Zhao Q Y, Zheng L Q and Ding X H 2011 Solid State Sci. 13548 